\title{
The Cure Behavior of Vinyl Ester Resin with Low Profile Additive I. Cure Kinetics and TTT Cure Diagram
}

\author{
Myung Sun HoNG and In Jae CHUNG* \\ Department of Chemical Engineering, Korea Advanced Institute of Science and Technology, \\ P.O. Box 150, Cheongryang, Seoul, Korea
}

(Received August 11, 1990)

\begin{abstract}
The isothermal cure of vinyl ester resins proceeds through several processes such as gelation, vitrification and behavior similar to autocatalysis. The cure kinetics of vinyl ester resins with poly(methyl methacrylate) or poly(vinyl acetate) as a low profile additive was analyzed by introducing a new kinetic model based on those processes. After the parameters in the model were determined through dynamic differential scanning calorimetry, the kinetic model was compared with isothermal DSC results. By using this model time-temperature-transformation (TTT) cure diagram was also plotted. The gelation time and vitrification time calculated from the kinetic model show good agreement with experimental values. Vinyl ester resin with a compatible low profile additive (i.e., PVAC) showed faster gelation but slower vitrification than the vinyl ester resin with an incompatible low profile additive (i:e., PMMA).

KEY WORDS Vinyl Ester Resin/ Low Profile Additive / Gelation / Vitrification / Autocatalytic Behavior / TTT Cure Diagram /
\end{abstract}

Vinyl ester is a reaction product of an epoxy resin with an ethylenically unsaturated carboxylic acid such as methacrylic acid or acrylic acid. ${ }^{1,2}$ It can be dissolved in styrene to give a liquid resin which is used like a styrenated unsaturated polyester resin. This liquid resin is called "vinyl ester resin."

Generally the vinyl ester resin is better in toughness and chemical resistance ${ }^{3}$ and has the lower volumetric shrinkage than unsaturated polyester resin. But it has the higher shrinkage than the parent epoxy resin. So, its shrinkage should be prevented during the cure reaction and the additives for this purpose is named a low profile additive. , $^{4}$

The isothermal cure of vinyl ester resin is characterized by gelation and vitrification like a general thermosetting polymer. The cure of thermosetting resins is complicated by the interaction of chemical kinetics and changing

\footnotetext{
* To whom all correspondence should be addressed.
}

physical properties with the cure. ${ }^{6}$ Several researchers have studied the curing kinetics of thermosetting resin under isothermal condition. ${ }^{7,8}$

In our study, a new kinetic model was developed on the cure behavior such a autocatalysis, gelation, and vitrification and the parameters were determined through dynamic DSC experiment for the neat vinyl ester resins and mixtures with low profile additives. Then this model was compared with isothermal DSC experiment and applied to TTT cure diagram.

\section{THEORY}

\section{Modeling of Cure Kinetics}

Isothermal cure of vinyl ester resin as a general thermosetting resins involves processes such as gelation and vitrification, ${ }^{6,9}$ to which 
one more process, autocatalysis, is added. Therefore, three processes of gelation, vitrification and autocatalytic behavior should be considered at the same time to develop a cure kinetic model of vinyl ester resin. Vitrification starts to occur when the glass transition temperature $\left(T_{\mathrm{g}}\right)$ reaches the cure temperature $\left(T_{\text {cure }}\right)$ and a rubbery state transforms to a gelled glass or a liquid state transforms to an ungelled glass even if gelation has not occurred. ${ }^{10,11}$ Since $T_{\mathrm{g}}$ increases with the degree of cure, the rate of cure will be dependent on the difference between $T_{\mathrm{g}}$ and cure temperature. The relationship between $T_{\mathrm{g}}$ and degree of cure is presented by $\mathrm{Di}$ Benedetto's equation. ${ }^{12}$

$$
\frac{T_{\mathrm{g}}-T_{\mathrm{g} 0}}{T_{\mathrm{go}}}=\frac{\left(E_{\mathrm{x}} / E_{\mathrm{m}}-F_{\mathrm{x}} / F_{\mathrm{m}}\right) X}{1-\left(1-F_{\mathrm{x}} / F_{\mathrm{m}}\right) X}
$$

where $T_{\mathrm{go}}$ is the glass transition temperature of the unreacted material, $E_{\mathrm{x}} / E_{\mathrm{m}}$ is the ratio of lattice energies for crosslinked and uncrosslinked polymer, $X$ is the degree of cure at $T_{\mathrm{g}}$, and $F_{\mathrm{x}} / F_{\mathrm{m}}$ is the corresponding ratio of segmental mobilities, a function of the distance between crosslinks.

For cure temperature below $T_{\mathrm{g}}$, the reactant is converted to glassy state and the reaction is retarded or quenched due to low diffusional and segmental mobilities. These mobilities are proportional to the available free volume of polymer at any temperature above and below $T_{\mathrm{g}} \cdot{ }^{13,14}$ Since the generalized WLF equation has been derived based on the free volume, it can be used as the frequency factor of the kinetic equation to represent the change of the intermolecular segment motion during curing reaction. Vitrification does not indicate necessarily the complete termination of reaction. Subsequent exposure to temperature, $\alpha$ degree higher than $T_{\mathrm{g}}\left(T_{\text {cure }}=T_{\mathrm{g}}+\alpha\right)$ could result in further reaction. ${ }^{6}$

Behavior similar to autocatalysis is also observed in the cure of vinyl ester resin. It is confirmed through experiments by DSC.
On the basis of the above, curing reaction kinetics can be written as follows:

$$
\begin{aligned}
\frac{\mathrm{d} X}{\mathrm{~d} t} & =\left(K_{1}+K_{2} X^{n}\right)(1-X)^{m} \\
& =K_{1}\left(1+\frac{K_{2}}{K_{1}} X^{n}\right)(1-X)^{m}
\end{aligned}
$$

where $n$ and $m$ are reaction orders, and $K_{1}$ and $K_{2}$, as follows

$$
\begin{aligned}
& K_{1}=K_{10} \exp \left[\frac{B\left(T-T_{\mathrm{g}}-\alpha\right)}{A+\left|T-T_{\mathrm{g}}-\alpha\right|}\right] \exp \left(-E_{1} / R T\right) \\
& K_{2}=K_{20} \exp \left[\frac{B\left(T-T_{\mathrm{g}}-\alpha\right)}{A+\left|T-T_{\mathrm{g}}-\alpha\right|}\right] \exp \left(-E_{2} / R T\right)
\end{aligned}
$$

Here $K_{10}$ and $K_{20}$ are the frequency factors, and $A$ and $B$, the WLF constants.

When the heating rate $(\mathrm{d} T / \mathrm{d} t=H)$ is constant, the reaction rate is given

$$
\frac{\mathrm{d} X}{\mathrm{~d} t}=H \frac{\mathrm{d} X}{\mathrm{~d} T}
$$

The substitution of eq 3 to eq 2 gives the following equaton:

$$
\begin{aligned}
\frac{\mathrm{d} X}{\mathrm{~d} T}= & \frac{K_{10}}{H} \exp \left(\frac{-E_{1}}{R T}\right) \exp \left\{\frac{B\left(T-T_{\mathrm{g}}-\alpha\right)}{A+\left|T-T_{\mathrm{g}}-\alpha\right|}\right\} \\
& \times\left[1+\frac{K_{20}}{K_{10}} \exp \left\{\frac{-\left(E_{2}-E_{1}\right)}{R T}\right\} X^{n}\right](1-X)^{m}
\end{aligned}
$$

The reaction orders, frequency factors, activation energies and WLF constants were determined from experimental data $(T, X$, $\left.\mathrm{d} X / \mathrm{d} t, \alpha, T_{\mathrm{g}}, H\right)$ by Marquardt's multivariable nonlinear regression method ${ }^{15}$ and Runge Kutta integration method. ${ }^{15}$

\section{Time-Temperature-Transformation (TTT)}

\section{Cure Diagram}

Estimation of the elapsed time to reach gelation and vitrification is very important and essential to thermosetting polymer processing. Therefore, it is important to plot a timetemperature-transformation (TTT) cure dia- 
gram which indicates the relation of the elapsed time and cure temperature. ${ }^{16}$

The differentiation of eq 1 gives

$$
\frac{1}{T_{\mathrm{go}}} \mathrm{d} T_{\mathrm{g}}=\frac{\left(E_{\mathrm{x}} / E_{\mathrm{m}}-F_{\mathrm{x}} / F_{\mathrm{m}}\right)}{\left\{1-\left(1-F_{\mathrm{x}} / F_{\mathrm{m}}\right) X\right\}^{2}} \mathrm{~d} X
$$

In the isothermal cure, the glass transition temperature changes with the reaction, and vitrification starts to occur when the temperature of the glass transition approaches the cure temperature i.e., $T_{\mathrm{g}}=T_{\text {cure }}{ }^{17}$ Therefore the elapsed time to the vitrification is calculated as follows:

From eq 3 and eq 4

$$
t_{\mathrm{vit}}=\frac{1}{K_{10}} \int_{0}^{X_{\mathrm{g}}} \frac{\mathrm{d} X}{\exp \left(\frac{-E_{1}}{R T}\right) \exp \left\{\frac{B\left(T-T_{\mathrm{g}}-\alpha\right)}{A+\left|T-T_{\mathrm{g}}-\alpha\right|}\right\}\left[1+\frac{K_{20}}{K_{10}} \exp \left\{\frac{-\left(E_{2}-E_{1}\right)}{R T}\right\} X^{n}\right](1-X)^{m}}
$$

where $X_{\mathrm{g}}$ is the degree of cure at $T_{\mathrm{g}}$ and calculated from eq 1 . In order to substitute the conversion term $(X)$ of eq 1 and eq 6 into the temperature term $\left(T_{\mathrm{g}}\right)$, eq 1 and eq 5 apply to eq 6. After these rearrangements, the time to vitrification can be calculated as a function of curing temperature from modified eq 6. Also, gelation occurs at a fixed extent of reaction as long as the reaction mechanism is not a function of temperature. ${ }^{10}$ Similarly the elapsed time to gelation, $t_{\text {gel }}$ can be calculated by putting $X_{\mathrm{g}}=X_{\mathrm{gel}}$ in eq 6 .

$$
t_{\mathrm{gel}}=\frac{1}{K_{10}} \int_{0}^{X_{\mathrm{gel}}} \frac{\mathrm{d} X}{\exp \left(\frac{-E_{1}}{R T}\right) \exp \left\{\frac{B\left(T-T_{\mathrm{g}}-\alpha\right)}{A+\left|T-T_{\mathrm{g}}-\alpha\right|}\right\}\left[1+\frac{K_{20}}{K_{10}} \exp \left\{\frac{-\left(E_{2}-E_{1}\right)}{R T}\right\} X^{n}\right](1-X)^{m}}
$$

The critical degree of cure at the gel point is obtained from viscosity measurement.

From these relationships, TTT cure diagrams of vinyl ester resins are obtained.

\section{EXPERIMENTAL}

\section{Materials}

Vinyl ester was prepared from epoxy resin (DGEBA, Kuk Do Chem., epoxy euivalent 185-190 g/eq.) and methacrylic acid (Aldrich Chem.). $1 \mathrm{~mol}$ of epoxy resin and $2 \mathrm{~mol}$ of methacrylic acid were mixed stoichiometrically with promotor, and inhibitor. $\mathrm{N}, \mathrm{N}$-dimethyl aniline (Aldrich Chem.) was used as a promotor. Hydroquinone was used as an inhibitor of methacrylic acid homopolymerization. Vinyl ester was synthesized at $90^{\circ} \mathrm{C}$ from the mixture with the ratio of (DGEBA+ methacrylic acid)/promotor/inhibitor $=100 / 1 /$ 0.005 by weight. After synthesis, the vinyl ester was dissolved into styrene at a molar ratio of vinyl ester/styrene $=1 / 2$. Two different types of low profile additives were used: $40 \mathrm{wt} \%$ poly(methyl methacrylate) and $40 \mathrm{wt} \%$ poly(vinyl acetate) dissolved in styrene. Benzoyl peroxide (Aldrich Chem.) and $\mathrm{N}, \mathrm{N}$-dimethyl aniline were also used as an initiator and promoter, respectively. Their compositions were controlled to have a ratio of vinyl ester resin (vinyl ester + styrene)/initiator/promotor $=100 / 2 / 1$ by weight for the cure reaction.

\section{ANALYSIS}

\section{Differential Scanning Calorimetry}

Differential scanning calorimetry (Du Pont model 910) was used to study the curing kinetics and determine the physical property such as glass transition temperature. Completion of the isothermal curing reaction was determined by the isothermal thermogram (i.e., the plot of the generation rate of heat $v s$. time) when it leveled off to the base line very close 
to the initial baseline. ${ }^{18}$ After completion of the isothermal curing reaction at a predetermined temperature, the sample was scanned with the heating rate of $1^{\circ} \mathrm{C} \mathrm{min}{ }^{-1}$ from $20^{\circ} \mathrm{C}$ to $200^{\circ} \mathrm{C}$ and residual heat $\left(Q_{\mathrm{R}}\right)$ was gained. Thus, the total amount of heat $\left(Q_{\text {Tor }}\right)$ generated by the cure reaction is the sum of heat generated during the isothermal cure $\left(Q_{\mathrm{r}}\right)$ and residual heat $\left(Q_{\mathrm{R}}\right)$, i.e., $Q_{\mathrm{Tot}}=Q_{\mathrm{T}}+Q_{\mathrm{R}}$.

From DSC data the following properties are determined.

1) Rate of Cure

$$
\frac{\mathrm{d} X}{\mathrm{~d} t}=\frac{1}{Q_{\mathrm{Tot}}} \frac{\mathrm{d} Q_{\mathrm{T}}}{\mathrm{d} t}
$$

2) Degree of Cure

$$
X=\frac{1}{Q_{\text {Tot }}} \int_{0}^{t} \frac{\mathrm{d} Q_{\mathrm{T}}}{\mathrm{d} t} \mathrm{~d} t
$$

3) Vitrification Time

The time required to reach vitrification was determined by the isothermal thermogram at various temperatures. Vitrification refers to the phase transition from liquid or rubbery state to glassy state, which results in retardation and quenching of curing reaction. Hence the vitrification time was defined as the time when cure reaction is completed under isothermal condition and in turn, the isothermal thermogram leveled off to the baseline very close to the initial baseline.

4) Glass Transition Temperature $\left(T_{\mathrm{g}}\right)$

After completion of the isothermal curing reaction at a predetermined temperature, the sample was quenched to room temperature. Then the sample was heated from room temperature to $200^{\circ} \mathrm{C}$ with the heating rate of $1^{\circ} \mathrm{Cmin}^{-1}$. The glass transition temperature is defined as the temperature at which the dynamic thermogram (i.e., the plot of the generation rate of heat $v s$. temperature) returns to the initial baseline after peak generation.

5) Kinetic Parameters

Kinetic parameters such as reaction orders $(m, n)$ frequency factors $\left(K_{10}, K_{20}\right)$ and activa- tion energies $\left(E_{1}, E_{2}\right)$ were determined by dynamic experiment. Dynamic experiment was carried out from $20^{\circ} \mathrm{C}$ to $200^{\circ} \mathrm{C}$ at the heating rate of $1^{\circ} \mathrm{C} \mathrm{min}{ }^{-1}$. The detailed procedure evaluating the kinetic parameters has been described already.

\section{Viscosity Measurement and Gelation Time}

The viscosity of vinyl ester resins was measured at various temperatures by a Brookfield viscometer with a temperature controlled heating chamber. The spindle was used at a steady shear rate of $9.3 \mathrm{~s}^{-1}$.

Gelation time was defined as the time when the viscosity increased very rapidly toward an infinite value. ${ }^{4}$

\section{RESULTS AND DISCUSSIONS}

\section{Modeling of Cure Kinetics}

Figure 1 describes the amount of heat generated $\left(Q_{\mathrm{T}}\right)$ during the isothermal cure of vinyl ester resin, neat and with low profile additives of $20 \mathrm{wt} \%$. Since the reactant does not totally cure under isothermal conditions, residual heat $\left(Q_{\mathrm{R}}\right)$ is released when the resins

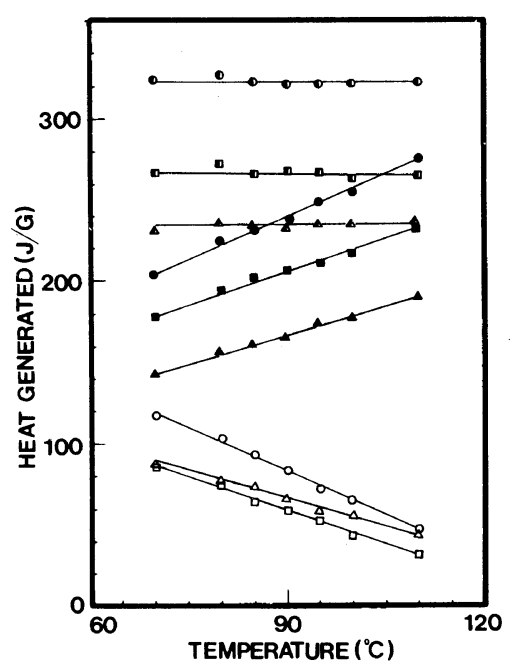

Figure 1. Heat generated during isothermal cure for vinyl ester resins, neat and with low profile additives of $20 \mathrm{wt} \%$ : isothermal heat (closed), residual heat (opened), total heat (semi-closed); neat (O), PMMA ( $\triangle$ ), PVAC ( $\square$ ). 


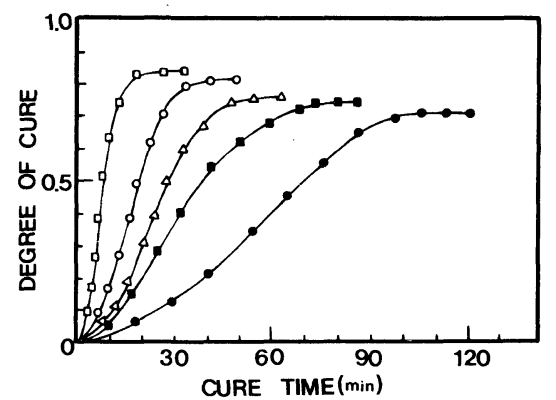

Figure 2. Degree of cure versus cure time for neat vinyl ester resin at various temperatures $\left({ }^{\circ} \mathrm{C}\right): 85(\mathbf{O}), 90(\square)$, $95(\triangle), 100(\bigcirc), 110(\square)$.

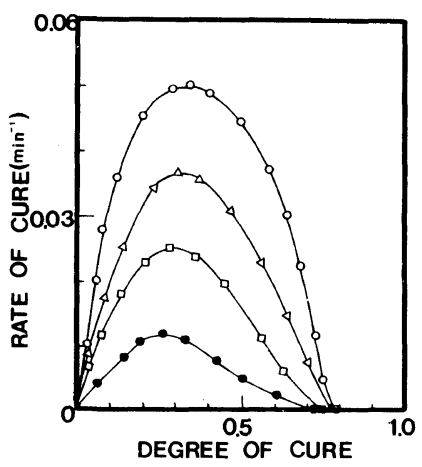

Figure 3. Rate of cure versus degree of cure for neat vinyl ester resins at various cure temperatures $\left({ }^{\circ} \mathrm{C}\right): 85(\mathrm{O}), 90$ $(\square), 95(\triangle), 100(\bigcirc)$.

are exposed to a higher temperature than the isothermal cure temperature. The total heat $\left(Q_{\text {Tot }}\right)$, the sum of isothermal heat and residual heat, is constant as shown in Figure 1. On the basis of the total heat and isothermal heat, the degree of cure is defined according to eq 8 and eq 9 respectively.

Figure 2 describes the degree of cure versus cure time for neat vinyl ester resin at various cure temperatures. Incomplete cure under isothermal condition and the increase in the final degree of cure along with cure temperature are due to vitrification which occurs when the glass transition temperature approaches the cure temperature. Vitrification gives rise to structural change from a liquid or rubbery state to a glassy state, which retards or quenches the molecular mobility. Hence the phenomena as
Table I. Total heat and parameters of Di Benedetto's equation

\begin{tabular}{cccccc}
\hline $\begin{array}{c}\text { Sample } \\
\text { code }\end{array}$ & $Q_{\mathrm{Tot}} / \mathrm{Jg}^{-1}$ & $E_{\mathbf{x}} / E_{\mathrm{m}}$ & $F_{\mathbf{x}} / F_{\mathrm{m}}$ & $T_{\mathrm{g} 0} / \mathrm{K}$ & $T_{g \infty 0} / \mathrm{K}$ \\
\hline VS & 323.9 & 0.97 & 0.6 & 261 & 422 \\
PMMA10 & 284.1 & 0.95 & 0.58 & 262 & 429 \\
PMMA20 & 235.1 & 0.95 & 0.58 & 263 & 431 \\
PVAC10 & 292.8 & 0.98 & 0.61 & 259 & 416 \\
PVAC20 & 267.1 & 0.98 & 0.61 & 257 & 413 \\
\hline
\end{tabular}

Remark: VS, neat Vinyl ester resin; PMMA10, vinyl ester resin with poly(methacrylate) of $10 \mathrm{wt} \%$; PMMA20, vinyl ester resin with poly(methyl methacrylate) of $20 \mathrm{wt} \%$; PVAC10, vinyl ester resin with poly(vinyl acetate) of $10 \mathrm{wt} \%$; PVAC20, vinyl ester resin with poly(vinyl acetate) of $20 w t \%$.

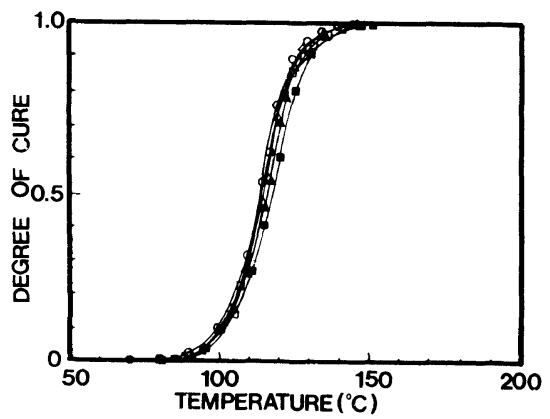

Figure 4. Degree of cure versus cure temperature for vinyl ester resin, neat and with low profile additives: neat

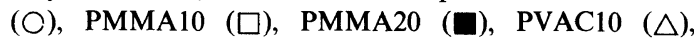
PVAC20 ( $\Delta)$. lines were evaluated from the kinetics model.

shown in Figure 2 take place.

Figure 3 describes the rate of cure versus degree of cure for neat vinyl ester resins at various cure temperatures. The figures show maximum rates which exhibit increasing values with cure temperature. Such behavior is observed in the autocatalytic reaction. ${ }^{8}$

Isothermal cure proceeds through several processes such as gelation and vitrification. Therefore, it may be necessary to investigate the relation between the glass transition temprature $\left(T_{\mathrm{g}}\right)$ and degree of cure $(X)$. This relation is expressed by using Di Benedetto's equation. Table I shows the experimental values of parameters in the equation. 
Table II. Kinetic parameters evaluated from kinetic model

\begin{tabular}{|c|c|c|c|c|c|c|c|}
\hline \multirow{2}{*}{$\begin{array}{l}\text { Sample } \\
\text { code }\end{array}$} & \multirow{2}{*}{$m$} & \multirow{2}{*}{$n$} & \multirow{2}{*}{$K_{10}$} & \multirow{2}{*}{$K_{20}$} & $E_{1}$ & $E_{2}$ & \multirow{2}{*}{$\alpha$} \\
\hline & & & & & \multicolumn{2}{|c|}{$\mathrm{cal} \mathrm{g} \mathrm{mol}^{-1}$} & \\
\hline vS & 0.77 & 0.69 & $8.32 \times 10^{11}$ & $7.79 \times 10^{10}$ & 24010 & 21320 & -10 \\
\hline PMMA10 & 0.66 & 0.54 & $7.18 \times 10^{11}$ & $5.57 \times 10^{10}$ & 24030 & 21350 & -10 \\
\hline PMMA20 & 0.65 & 0.52 & $7.01 \times 10^{11}$ & $5.43 \times 10^{10}$ & 24070 & 21380 & -10 \\
\hline PVAC10 & 0.71 & 0.61 & $7.53 \times 10^{11}$ & $5.99 \times 10^{10}$ & 24050 & 21260 & -10 \\
\hline PVAC20 & 0.69 & 0.59 & $7.23 \times 10^{11}$ & $5.52 \times 10^{10}$ & 24080 & 21240 & -10 \\
\hline
\end{tabular}

Figure 4 describes dynamic curing behavior at a heating rate of $1{ }^{\circ} \mathrm{C} \mathrm{min}{ }^{-1}$. From these dynamic thermograms and relations between $T_{\mathrm{g}}$ and degree of cure, the parameters in eq 4 can be calculated. From experimental data $(T$, $\left.X, \mathrm{~d} X / \mathrm{d} T, T_{\mathrm{g}}, H, \alpha\right)$, kinetic parameters such as reaction orders $(m, n)$, frequency factors $\left(K_{10}, K_{20}\right)$, activation energies $\left(E_{1}, E_{2}\right)$ and WLF equation constants (A, B) were determined by Marquardt's multivariable nonlinear regression method and Runge Kutta integration method.

The kinetic parameters are summarized in Table II. The constants (A and B) in WLF equation are regressed to unity. The lines in Figure 4 are calculated from the kinetic model with experimentally determined parameters. They show good agreement with the experimental data.

The cure of vinyl ester resins occurs mostly through free radical copolymerization between the vinyl group of vinyl ester and styrene. The addition of low profile additives affects the cure kinetics to give lower values of the reaction rate constant, frequency factor, and $Q_{\text {Tot }}$ because of the topological resistance to the molecular contact of reactive vinyl ester and styrene. The vinyl ester resin with PMMA has two phases, the continuous phase and dispersed phase, even before the cure begins. ${ }^{4}$ The continuous phase contains the vinyl ester and the styrene, and the dispersed phase contains the styrene and PMMA.

The restriction to molecular contact of reactive vinyl ester and styrene in the con- tinuous phase, becomes more pronounced as the curing reaction proceed, because of the increase in viscosity. As the diffusion control becomes progressively more prominent, the reactive vinyl ester and styrene in the vicinity of low profile additives are shielded and hence are more difficult to encounter each other than the reactive species in the neat vinyl ester resin. This seems to bring about low values of cure rate, freqeuncy factor and reacton order in vinyl ester resins with low profile additives.

\section{Gelation and TTT Cure Diagram}

Gelation occurs at a certain extent of reaction under isothermal conditions by the formation of a crosslinked network. ${ }^{10}$ The curing reaction in the mixture of vinyl ester and styrene monomers is a free radical chain growth polymerization. There are four possible reactions: 1) Intermolecular crosslinking between $\mathrm{C}=\mathrm{C}$ bonds of vinyl ester and styrene monomer, 2) intermolecular crosslinking between $\mathrm{C}=\mathrm{C}$ bonds of vinyl esters, 3 ) branching on the vinyl ester by styrene, and 4) styrene homopolymerization. Although all the reactions affect the cure kinetics, mainly reaction 1) and 2) contribute to crosslinked network, which results in the gelation.

Gelation time was determined by measuring viscosity change. Figure 5 gives plots of viscosity versus cure time at a $90^{\circ} \mathrm{C}$ cure temperature for the mixture of vinyl ester resin and low profile additives. The viscosity was measured at steady shear rate of $9.3 \mathrm{~s}^{-1}$. As shown in Figure 5 the viscosity increases slowly 


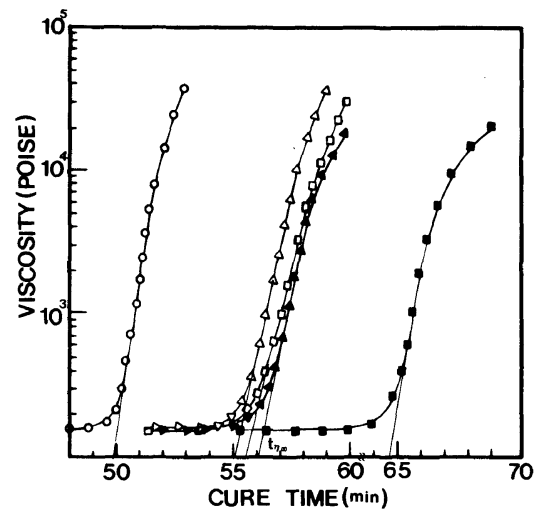

Figure 5. Viscosity versus cure time for vinyl ester resin, neat and with low profile additives at $100^{\circ} \mathrm{C}$ : neat $(O)$,

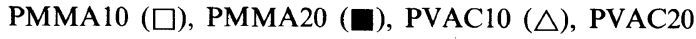
(A).

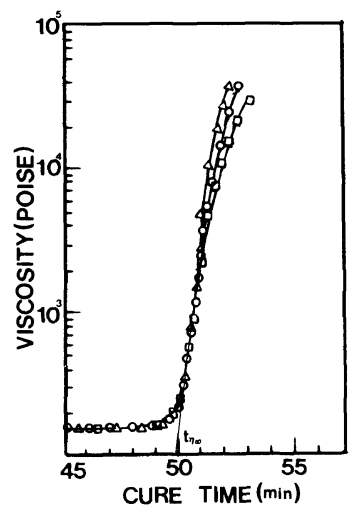

Figure 6. Viscosity at different shear rate versus cure time for neat vinyl ester resin at $90^{\circ} \mathrm{C}$ : Shear rate; $4.65 \mathrm{~s}-1(\triangle)$, $9.3 \mathrm{~s}^{-1}(\bigcirc), 18.6 \mathrm{~s}^{-1}(\square)$.

during the early stage of cure and then increases very rapidly. Similar phenomona are shown at different temperatures. We defined from this experiment the gel point $\left(t_{\eta_{\infty}}\right)$ at which the - viscosity changes abruptly. ${ }^{4}$ Figure 6 shows viscosity changes for different shear rates. The point at which the viscosity changes abruptly was constant, irrespective of the steady shear rate. This implies that gel point is reasonably accepted although it was measured from the rheological property such as viscosity.

Table III presents values of $t_{\eta \infty}$ for various temperatures. The gelation time for neat vinyl
Table III. Comparisons of gelation times and critical degrees of cure $\left(X_{\mathrm{gel}}\right)$

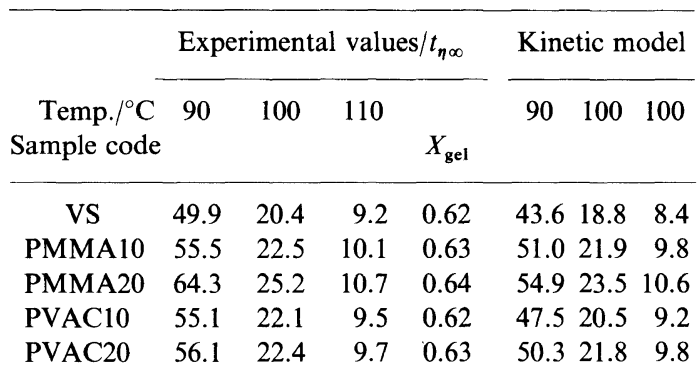

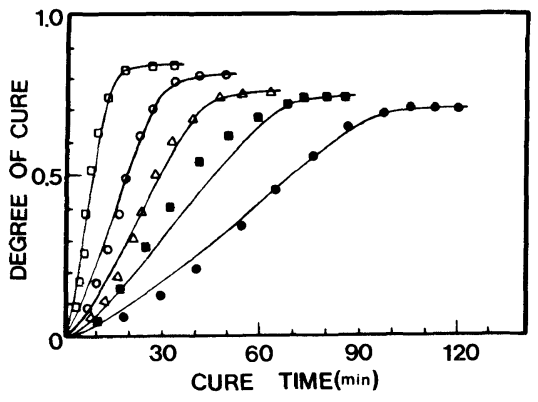

Figure 7. Degree of cure versus cure time for neat vinyl ester resin at various temperatures $\left({ }^{\circ} \mathrm{C}\right): 85(\mathbf{O}), 90(\mathbf{\square})$, $95(\triangle), 100(\bigcirc), 110(\square)$. lines were evaluated from the kinetics model.

ester resin is shortest, whereas the time for PMMA20 sample is longest. The gelation time becomes longer when the content of additives increases. This may be explained as Han's description $^{4}$ and our experimental results ${ }^{19}$ that PMMA and styrene monomer are coagulated and form small droplets. Both promotor and initiator may be absorbed into those droplets causing low concentrations of promotor and initiator available for the copolymerization of vinyl ester with styrene. This will bring about a slow cure.

Figure 7 describes the cure time versus degree of cure in neat vinyl ester resin and compare kinetic model and isothermal DSC presults. When the temperature is low, the line calculated from the kinetic model deviates a little from the isothermal DSC results. However, as the curing temperature increases, 
Table IV. Comparisons of vitrification times

\begin{tabular}{|c|c|c|c|c|c|c|}
\hline \multirow[b]{2}{*}{$\begin{array}{l}\text { Temp } /{ }^{\circ} \mathrm{C} \\
\text { Sample coc }\end{array}$} & \multicolumn{2}{|c|}{ Kinetics model } & \multicolumn{4}{|c|}{ Isothermal DSC } \\
\hline & $e^{80}$ & $100 \quad 110$ & 80 & 90 & 100 & 110 \\
\hline
\end{tabular}

$\begin{array}{lllllllll}\text { VS } & 169.0 & 75.5 & 35.6 & 17.7 & 155.5 & 69.0 & 32.9 & 15.9\end{array}$ $\begin{array}{llllllllll}\text { PMMA10 } & 189.5 & 83.9 & 39.1 & 19.1 & 185.0 & 76.8 & 33.8 & 16.2\end{array}$ $\begin{array}{lllllllll}\text { PMMA20 } & 198.1 & 87.6 & 40.7 & 19.8 & 195.3 & 83.7 & 36.8 & 17.8\end{array}$ $\begin{array}{llllllllll}\text { PVAC10 } & 189.6 & 85.1 & 40.3 & 20.2 & 191.3 & 86.1 & 37.8 & 17.9\end{array}$ $\begin{array}{lllllllll}\text { PVAC20 } & 200.8 & 90.3 & 42.9 & 21.6 & 199.4 & 87.5 & 39.2 & 18.9\end{array}$

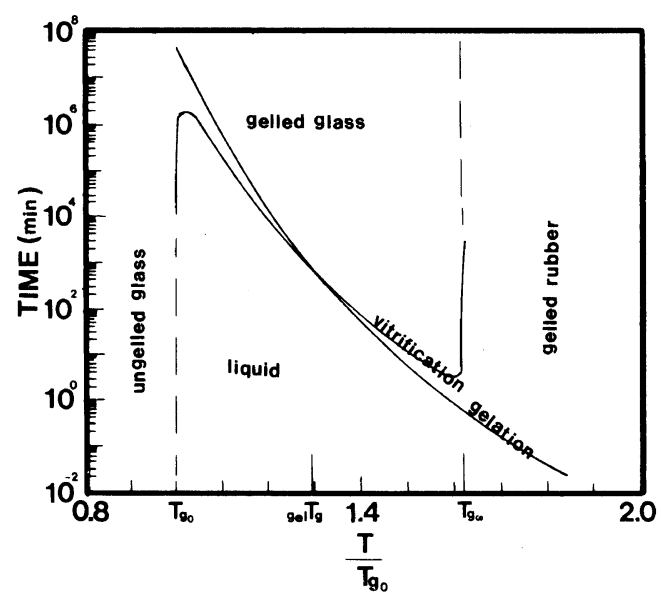

Figure 8. TTT cure diagram of neat vinyl ester resin.

the kinetic model fits very well the isothermal DSC results. They show good agreement in the region where gelation starts to occur and then vitrification take place.

Therefore we can estimate the gelation time and vitrification time from the new kinetic model as shown in Tables III and IV. The new kinetic model is considered a powerful method for TTT cure diagram, which can predict the physical states of reaction mixture depending on the temperature and degree of cure. Hence the TTT cure diagram plays a key role in estimation of the elapsed time to reach gelation and vitrification which is very important and essential to thermosetting polymer processing.

Figure 8 is a TTT cure diagram for neat vinyl ester resin. Other diagrams for vinyl ester resins with low profile additives are almost in- distinguishable and hence not drawn.

The TTT cure diagram is characterized by three principal temperature ${ }^{16}: T_{\mathrm{g} 0}$, glass transition temperature at the initial stage of cure; ${ }_{\mathrm{gel}} T_{\mathrm{g}}$ temperature at which the gelation and vitrification times are the same; and $T_{\mathrm{g} \infty}$, maximum glass transition temperature of the fully cured system. In the region of $T_{\text {cure }}<T_{\mathrm{g} 0}$, no reaction occurs because the reactive species are immobilized in the glassy state. In the region of $T_{\mathrm{g} 0}<T_{\text {cure }}<T_{\mathrm{g} \infty}$, the system exists as liquid phase until gelation or vitrification occurs. Then below ${ }_{\text {gel }} T_{\mathrm{g}}$, if gelation has not occured, the liquid phase transforms the ungelled glass, whereas if gelation has occured, it transforms the gelled glass. Above ${ }_{\text {gel }} T_{\mathrm{g}}$, the liquid phase trasforms the gelled rubber after gelation and then the gelled glass after vitrification. In the region of $T_{\text {cure }}>T_{\mathrm{g} 0}$, it transforms the gelled rubber after gelation and does not vitrify. Thus there are four physical states, which are liquid, ungelled glass, gelled rubber, gelled glass states during curing reaction.

Table III also present the gelation time evaluated from kinetic model after the parameters were calculated from the dynamic experimental data. Vitrification times determined from kinetic model and isothermal DSC experiment are compared in Table IV and show good agreement.

The addition of PVAC gives the shorter gelation time but longer vitrification time than the addition of PMMA. In other words, compatible and more flexible low profile additives (i.e., PVAC) give faster curing times than the incompatible low profile additives (i.e., PMMA) until gelation, whereas after network formation by gelation, it may be less glassed and then later quenched.

It seems that differences in curing behavior among the vinyl ester resin, neat and with PVAC or PMMA depend on structure and morphology due to the compatibility of the respective low profile additives with the vinyl ester resin. 
Therefore, we shall discuss the structure, morphology and mechanical property of vinyl ester resin with low profile additives in next publication. ${ }^{19}$

\section{CONCLUSIONS}

A kinetic model based on the phenomena of gelation, vitrification, and behavior similar to autocatalysis was developed. Time-temperature-transformation cure diagram was plotted from the kinetic model. The kinetic model, the parameters of which were calculated from dynamic DSC experiment, was comparatively coincident with isothermal DSC results. Also, the gelation time and vitrification time calculated from the kinetic model showed a good agreement with experimental values. The addition of low profile additives slowed the cure rate of vinyl ester resin. In the vinyl ester resin with low profile additives, compatibility between vinyl ester resin and low profile additives had effect on the cure reaction. Vinyl ester resin with a compatible low profile additive (i.e., PVAC) showed faster gelation but slower vitrification than the vinyl ester resin with an incompatible low profile additive (i.e., PMMA).

\section{REFERENCES}

1. R. E. Young, "Unsaturated Polyester Technology," P. E. Bruins, Ed., Gordon and Breach, New York, N.Y., 1976, p 315.

2. S. H. Goonman, "Handbook of Thermoset Plastics,"
Noyes Publications, New Jersey, 1986, p 76.

3. S. H. Rider and E. E. Hardy, "Polymerization and Polycondensation Processes," N. A. J. Platzer, Ed., Adv. Chem. Ser. 34, The American Chemical Society, Washington, D. C., 1962.

4. C. D. Han and K. W. Lem, J. Appl. Polym. Sci., 28, 3155 (1983).

5. P. R. Paul and S. Newman, "Polymer Blends," Vol. 2, Academic, New York, N.Y., 1978.

6. J. B. Enns and J. K. Gillham, J. Appl. Polym. Sci., 28, 2567 (1983).

7. M. R. Kamal and S. Sourour, Polym. Eng. Sci., 13, 59 (1973).

8. J. Mijovic, J. Appl. Polym. Sci., 31, 1177 (1986).

9. D. H. Kim and S. C. Kim, Polym. Bull., 18, 533 (1987).

10. P. J. Flory, "Principles of Polymer Chemistry," Cornel University Press, New York, N.Y., 1953.

11. S. Lunka, J. Vladyka, and K. Dusek, Polymer, 19, 931 (1978).

12. A. T. Benedetto and L. E. Nielson, J. Macromol. Sci. Rev, Rev. Maacromol. Chem., C3, 69 (1969).

13. K. D. Rusch, J. Macromol. Sci. Phys., B2(2), 179 (1968).

i4. K. D. Rusch and R. H. Beck, J. Macromol. Sci. Phys., B(3), 365 (1965).

15. J. L. Kuester and J. M. Mize, "Optimization Techniques with FORTRAN," McGraw-Hill, New York, N.Y., 1973.

16. J. K. Gillham, "Torsional Braid Analysis (TBA) of Polymers,” J. V. Dawkins, Ed., Applied Science, London, 1982, Chapter 5.

17. J. K. Gillham, "Epoxy Resins and Composites III," K. Dusek, Ed., Springer-Verlag, Berlin, Heidelberg, 1986.

18. G. L. Hagnauer, B. R. Laliberte, and D. A. Dunn, Preprint, Organic Coat Plastics, The American Chemical Society, A6, 646 (1982).

19. M. S. Hong and I. J. Chung, "The cure behavior of vinyl ester resin with low profile additives, Part II. Morphology and mechanical property," submitted in Polym. J. 